\title{
Dimensional management practices to improve product development: application at a brazilian automotive plant
}

\author{
Francisco Uchoa Passos, Ricardo Coutinho Cerqueira \\ SENAI CIMATEC \\ e-mails: francisco.uchoo@fieb.org.br ; rcoutinho2@hotmail.com
}

\begin{abstract}
This paper aims to propose improvements to the process of dimensional management that is currently practiced in a Brazilian vehicle manufacturing plant. A review of the Dimensional Management for the Product Development enabled us to propose a construct of work practices that are designated to be inserted into the product development of the plant. A critical analysis was subsequently performed in a sample of dimensional nonconformities that occurred late in the product development phases. To avoid that nonconformities, a set of dimensional management practices for the plant was established in accordance with the construct. The proposed practices cover the whole process of new product development. The paper explains how a set of work practices was established for two identified process failures in detail for better illustration of the proposed methodology. It is supposed that the implementation of the new set of practices has supported the product development team to develop better vehicle quality and reduce the costs and cycle timing.
\end{abstract}

Keywords: design for dimensional control, product development management, interactive design and manufacturing, automotive industry.

\section{Introduction}

To ensure sustainability in today's competitive global market, manufacturing organizations must properly balance three critical variables: cost, quality and delivery time. In the case of the automotive industry, with new entrants into the market -- particularly Chinese and Indian automakers who have been achieving lower product costs -- quality has become a critical factor in survival, particularly for the traditional American, European and Japanese automotive industries. Thus, in addition to needing to reduce the cost of vehicles, these industries also find themselves faced with the challenge of raising the quality of their products, which has come to be observed as a differential in customers' purchasing decisions.

It is known that dimensional variation arising from the manufacturing and assembly of multi-component products, such as vehicles, is a factor that is involved in the degradation of product quality. The variations affect the aesthetics and functionality of the product. Dimensional mismanagement leads to low quality and its consequences, and this mismanagement is reflected in increases in costs, delivery times and production cycles.

In the 1970s and 1980s, quality tools, such as Statistical Process Control (SPC), that aimed to manage dimensional variation gained prominence in vehicle production. As is known, SPC is the application of statistical methods to monitor and control variations in manufacturing processes to ensure the production of compliant products. SPC was the main tool that enabled manufacturing engineers to examine a process and its sources of variation in an objective manner, allowing the early detection and prevention of problems. SPC therefore prevented nonconforming products from reaching customers. Despite the major contribution of this tool, SPC could only be employed when the product was in production. That is, designs that were susceptible to dimensional variations left manufacturing with the legacy of living with these problems, which resulted in the need for an increasingly stringent SPC, leading to higher production costs and increased cycle times. Later, in the 1990s, the need was established to develop designs that were more robust to these dimensional variations. In the automotive industry, these designs began to take into account the effect of the accumulation of variations inherent in the manufacture and assembly processes on the functional and aesthetic attributes of the vehicle. This need gave rise to the Design for Dimensional Control (DDC), which is an engineering methodology combined with computational simulation tools that seeks to: (a) understand the sources of variation; (b) select product characteristics and manufacturing processes that minimize variation; and (c) use suitable methods to communicate the expected level of variation and designated ways to control the variation. In this scenario, the SPC becomes only one part of a broader 
set of practices. The primary objective is to create a design and process that absorbs as much variation as possible without affecting the functionality and aesthetics of the product. The importance of this discipline is evident within manufacturing organizations that seek to achieve global competitiveness and status for their products and processes.

According to Liggett (1993), the pillars of DDC are as follows:

- Computer simulation -- analytical methods for calculating the accumulation of tolerances in an assembly process;

- Geometric Dimensioning and Tolerancing (GD\&T) -- Clear elucidation and definition of technical specifications for systems, sub-systems and components, ranging from the release of engineering drawings to the definition of plans for manufacturing control;

- Statistical Process Control (SPC) -- monitoring to keep the process under control according to specifications defined in the manufacturing control plan; and

- Dimensional Variation Management -- an integrated set of management actions practiced from product development to production to ensure the flow of clear communication from engineering to manufacturing and vice versa.

Bibliographic references covering the first three pillars of DDC are widely available. However, the same cannot be said of dimensional variation management, and this issue has been addressed in large enterprises in a non-structured way, highlighting the lack of practical application of dimensional variation management models and methods.

This work identifies this gap and presents a proposal for a structured set of improvements in the dimensional variation management of an automaker. Opportunities for improvement were identified from the study of a sample of dimensional nonconformities occurring late in product development. This work was carried out in a company wishing to identify the failures of its current dimensional variation management process that lead to the occurrence of such nonconformities. The following are practical suggestions for improvement that are supported by the available literature on the subject. It is assumed that the proposed practices will allow nonconformities to be anticipated when the design phase of the product is still underway, generating solutions to optimize both design and the corresponding manufacturing process. The issue of dimensional variation is thus intended to be treated in a more structured manner by the automaker, resulting in direct or indirect cost savings arising from reductions in (a) development and production costs, (b) customer warranty costs, (c) product delivery times to the market and (d) production cycle times.

\section{Literature review}

This section discusses the conceptual elements for building the construct of practices, highlighting the activities that from the perspective of the reviewed authors, relate to the issue of dimensional variation management at each stage of product development.

Initially, an overview of Design for Dimensional Control (DDC) will be presented, focusing on the dimensional variation management pillar, emphasizing its characteristics and its importance in supporting the development of complex products. This overview will be followed by a discussion of how dimensional variation management could be introduced into a generic model of the Product Development Process.

\subsection{Design for Dimensional Control (DDC)}

As Huang (1996) notes, DDC centers around dimensional variation management during the design, manufacturing and assembly of products such that the product still meets its functional and/or aesthetic objectives, even when considering extreme variation conditions. The goal of DDC is not to eliminate dimensional variation, which would be virtually impossible, but to "manage it", that is, to understand the sources of variation, how they behave and their impact on the functionality and/or aesthetics of the end product and, by so doing, facilitate the development of optimized designs that are not susceptible to these variations such that customer expectations can be met at the lowest possible cost.

According to Sleath and Leaney (1997), implementing DDC leads to the minimizing of product development costs by "making sure" during the design phase. This process avoids the delays and elevated costs that are associated with design modifications after the design has been consolidated, such as those occurring during prototype construction or, even worse, during the production phase. Another advantage is that production costs are kept low by reducing the need to adjust or rework, thereby reducing waste. The implementation of DDC also helps to reduce the need for high precision parts, accurate assembly operations and rigorous quality control.

Huang (1996) states that DDC provides the following benefits: (a) ease of manufacturing and assembly (less rework and waste), (b) better fit and finish, favorably impacting product aesthetics and perceived quality by the consumer, (c) reduction in the need to make minor modifications on the "factory floor", (d) improved manufacturing flow (fewer steps or adjustment operations), (e) reduction of cycle times, (f) reduction of complexity (fewer design changes and simpler manufacturing operations), (g) increased consistency and reliability and (h) improved maintainability and ease of repair. According 
to him, DDC and DFMA (Design for Manufacture and Assembly) have complementary approaches for reduction of dimensional variation. While DDC is concerned with variability reduction in terms of size and form of a product's design, DMFA is concerned with product simplification and part count reduction.

DDC is based on the use of analytical tools to quantify the impact that inherent process variations have on the attributes and performance of the final product. However, DDC has proved to be more than a simple design tool used in a certain stage of product development. In fact, DDC is relevant from the definition of the initial product specifications to its production, focusing on the issues and decisions that will determine the dimensional integrity of the final product. DDC comprises individual analytical tools and is a broad systemic approach that is aimed at ensuring dimensional integrity from the beginning to the end of product development and production within the dimensional variation management pillar (CRAIG, 1997). The following discusses how dimensional variation management practices relevant to DDC could occur in the various stages of the integrated development and production processes of a complex product.

\subsection{Dimensional variation management in the PDP}

To point out DDC activities during product development, we used the generic model for the Product Development Process - PDP (ROZENFELD et al., 2006). Based on the five phases of the process, some practices of dimensional variation management - as recommended in the reviewed literature - are summarized below for each phase of the PDP, emphasizing the aesthetic and functional requirements of the automotive design.

\section{- Dimensional Management in the Informational Design}

Craig (1996) explains that the first goal of a robust dimensional variation management process is to obtain a clear definition of the dimensional requirements (functional and aesthetic) of the product. In the case of an automotive product, "gaps" and "leveling" between adjacent parts, known as gap and flushness, respectively, can be cited as examples of aesthetic dimensional requirements that influence the consumer's perception of quality (perceived quality). The following may be cited as functional dimensional requirements: (a) variations in the spacing of sealing the doors against the body, called the seal gap, important for preventing the entrance of dust, water and "wind noise"; (b) wheel alignment angles, the variation of which has a direct influence on driving comfort; and (c) functional characteristics of assembly systems coupled to the body, such as the seats, fuel tank, engine and transmission, among others. Figures 1 and 2, respectively,

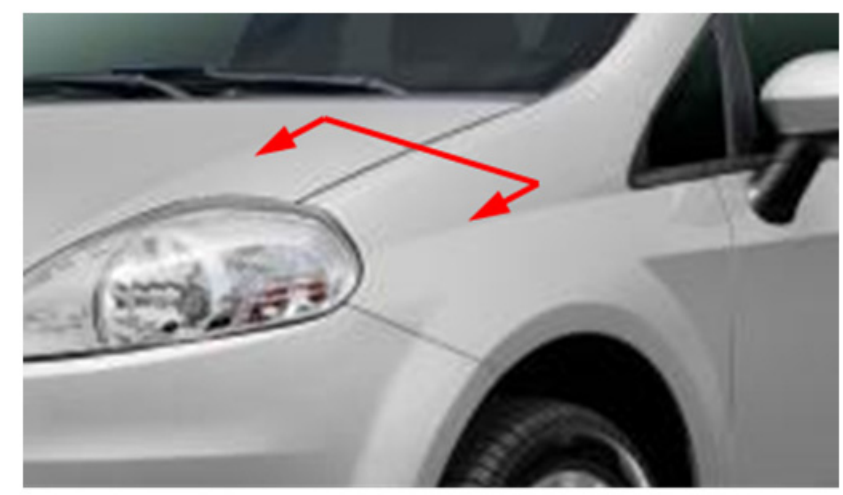

\section{Flushness}

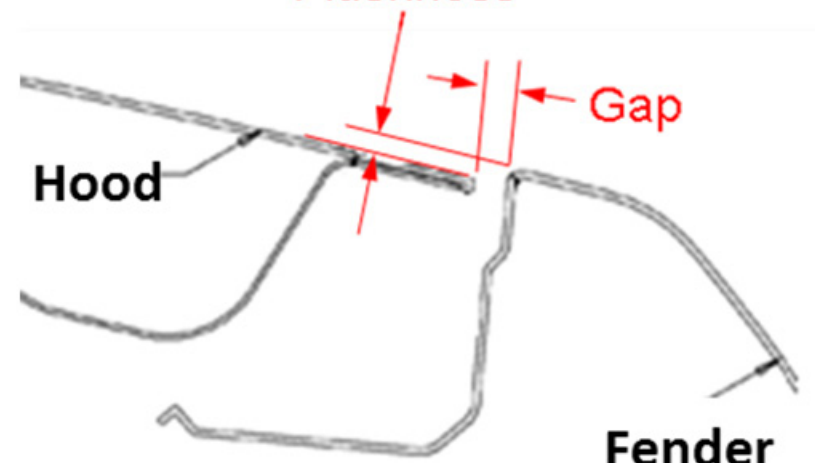

Figure 1. Example of an aesthetic dimensional requirement.
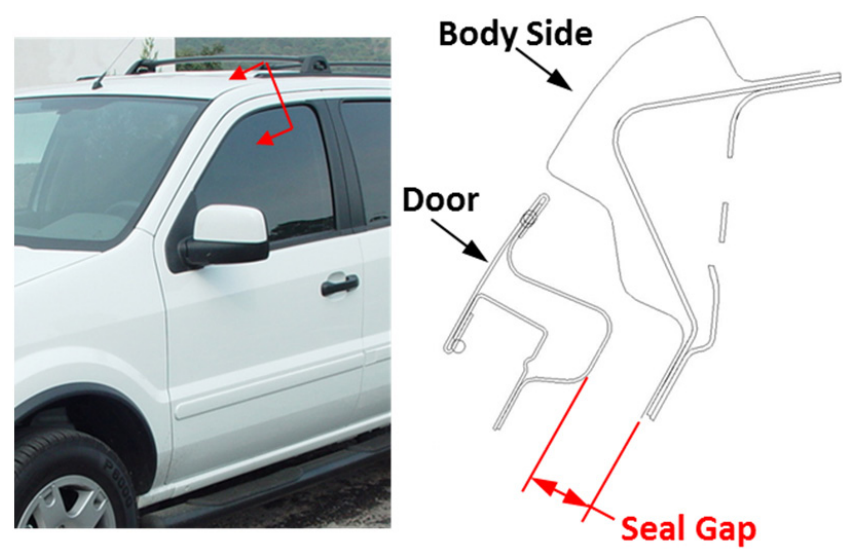

Figure 2. Example of a functional dimensional requirement.

show examples of the aesthetic and functional dimensional requirements for a car.

As Craig (1996) states, in terms of dimensional variation management, the information design phase ends with approval by senior design and manufacturing management and with key functional members of these teams approving of a formal document containing all of the product's dimensional requirements. As noted by Harper (1997), as the design evolves throughout the subsequent phases of product development, the requirements defined 
in the information design can be refined according to the engineering consensus.

- Dimensional Management in the Conceptual Design

The conceptual aesthetics of the product are also determined at this stage, starting by selecting from among the ideas generated (product style design themes) to identify the one that best meets the design attributes and that will be included in the subsequent phases of the project and appear in the final product. For dimensional variation management, the set of attributes related to the aesthetics, known in the automotive industry as the "perceived quality", is a key issue because that is what usually attracts the customer to purchase the product, i.e., it is what makes the product "pleasing" (PERCEIVED..., 2011). The aesthetic dimensional requirements have a direct impact on the perceived quality, and it is therefore vital to select themes or design concepts that simultaneously result in (a) the greatest possible robustness to the dimensional variations of these requirements and (b) the lowest possible susceptibility of the consumer to the negative perception of these dimensional variations. Leaney (1994) states that at this stage of the project, only "qualitative" analyses are adopted, comparing concepts in relation to one another and identifying the most robust concepts based on historical quality problems, benchmarking records, engineering experience and individual perceptions.

In summary, it can be said that the goal of dimensional variation management at this stage is to evaluate the technical dimensional feasibility of the product design concepts.

- Dimensional Management in the Detailed Design

According to Craig (1996) and Islam (2009), it is at this stage that dimensional variation management has the highest impact on the PDP and, accordingly, where it can add the greatest value to the product. This phase brings together three major goals of dimensional variation management. The first goal is to determine if the design, manufacturing and assembly process optimally meets the dimensional requirements of the product. The second goal is to ensure that dimensional management product documentation is correct. The third goal is to validate the product dimensional requirements against the physical prototypes plans (DANTAN, 2008a, b; MUSKE, 1997; LEANEY, 1994; ILLINGWORTH; McLEOD, 2007).

- Dimensional Management in the Production Preparation

In the Production Preparation phase the same approval criteria are used, but they are applied to products that are built using the definitive production equipment.

Craig (1996) states that from a dimensional variation management perspective, the goal at this stage is to verify if manufacturing capabilities achieve design intent, and it is here that the sixth goal of dimensional variation management during the PDP appears. To accomplish this goal, the first activity is the verification and validation of the assembly and measurement devices with respect to the intended design. The first step is therefore to work with the manufacturing team to ensure that the devices and methods of assembly, inspection and measurement reflect the intended design, i.e., that they ratify the concepts confirmed by the dimensional simulation models. It is known that many changes normally occur between the release of the design and the assembly of the product. What is important is that these modifications are reviewed and approved by the dimensional management team to ensure that the product requirements are still met, thereby ensuring product integrity.

The approval of the product/process occurs when the capability of the product can be demonstrated to meet its significant parameters within the tolerance specifications that were pre-established in the Detailed Design, thus obtaining approval for the commencement of the production of salable products.

\section{- Dimensional Management in the Product/Process} Monitoring

During this monitoring, needs or opportunities for improvement are identified and audits are conducted, as customer satisfaction evaluations, product performance monitoring and the recording of lessons learned that will be of great importance in the future for the development of new products.

Finally, the "lessons learned" should be recorded, classified in categories and made available at all times to the Product Development teams, aiming to capture useful knowledge for the realization of new designs. This activity is what Craig (1996) calls "production to design feedback loop", which is defined as the seventh and final goal of dimensional variation management during the PDP.

Table 1 presents a summary with the seven goals of dimensional variation management, distributed throughout the five PDP phases, with their respective recommended practices.

\section{Methodology}

To achieve the objective of proposing improvements to the current dimensional variation management process of the automaker, empirical research was conducted according to the following steps:

\section{Step 1 - Construction of the analysis model}

A table was constructed (see Table 2) for the analysis model that contained spaces for the following information: (1) the dimensional variation management goals for each phase of the PDP (see Table 1); (2) the types of current process failures for each goal, obtained from the analysis of the sample of dimensional nonconformities collected; (3) the causes and effects of these failures; (4) the current controls, i.e., the automaker's procedures to eliminate or 
Table 1. Goals and practices of dimensional variation management in PDP (based on Craig, 1996).

\begin{tabular}{|c|c|c|c|}
\hline PDP phases & & $\begin{array}{c}\text { Dimensional } \\
\text { Management goals }\end{array}$ & $\begin{array}{l}\text { Recommended } \\
\text { practices }\end{array}$ \\
\hline \multirow[t]{2}{*}{ Informational Design } & \multirow[t]{2}{*}{1} & \multirow[t]{2}{*}{$\begin{array}{l}\text { Clearly define product dimensional } \\
\text { requirements (aesthetic and functional) }\end{array}$} & $\begin{array}{l}\text { Create an illustrative document which summarizes all dimensional } \\
\text { requirements }\end{array}$ \\
\hline & & & Kano Diagram, QFD, Benchmarking \\
\hline \multirow[t]{3}{*}{ Conceptual Design } & \multirow[t]{3}{*}{2} & \multirow{3}{*}{$\begin{array}{l}\text { Evaluate the technical dimensional } \\
\text { feasibility of the product design concepts }\end{array}$} & Functional modeling of the product (top-down) \\
\hline & & & $\begin{array}{l}\text { Evaluate manufacturing methods that are required to meet the product } \\
\text { parameters }\end{array}$ \\
\hline & & & Qualitative analysis of product design concepts \\
\hline \multirow[t]{7}{*}{ Detailed Design } & \multirow[t]{3}{*}{3} & \multirow{3}{*}{$\begin{array}{l}\text { Determine if the design, manufacturing } \\
\text { and assembly process optimally meets the } \\
\text { dimensional requirements of the product }\end{array}$} & Dimensional Variation Analysis / Computer Aided Tolerancing \\
\hline & & & Dimensional optimization of design and process \\
\hline & & & Photorealism simulations to evaluate Perceived Quality attribute \\
\hline & \multirow[t]{3}{*}{4} & \multirow{3}{*}{$\begin{array}{l}\text { Ensure that dimensional management } \\
\text { product documentation is correct }\end{array}$} & GD\&T application according to dimensional variation analysis \\
\hline & & & Design and Process FMEAs \\
\hline & & & Manufacturing Control Plan creation \\
\hline & 5 & $\begin{array}{l}\text { Validate the product dimensional } \\
\text { requirements against the physical } \\
\text { prototypes }\end{array}$ & Manufacturing Control Plan implementation \\
\hline \multirow[t]{3}{*}{ Production Preparation } & \multirow[t]{3}{*}{6} & \multirow[t]{3}{*}{$\begin{array}{l}\text { Verify if manufacturing capabilities } \\
\text { achieve design intent }\end{array}$} & $\begin{array}{l}\text { Verification and validation of the assembly and measurement devices } \\
\text { with respect to the intended design - MSA }\end{array}$ \\
\hline & & & Validation of process changes \\
\hline & & & SPC - validation of process capability according to design intent \\
\hline \multirow{4}{*}{$\begin{array}{l}\text { Product/Process } \\
\text { Monitoring }\end{array}$} & \multirow[t]{4}{*}{7} & \multirow[t]{4}{*}{ Production to design feedback loop } & SPC - monitoring of product dimensional performance \\
\hline & & & $\begin{array}{l}\text { Fix dimensional issues coming from customers complaints and } \\
\text { quality indexes }\end{array}$ \\
\hline & & & $\begin{array}{l}\text { Update dimensional variation models with capability data of process } \\
\text { at hand, to drive improvement actions }\end{array}$ \\
\hline & & & $\begin{array}{l}\text { Record "lessons learned" and make available for the realization of } \\
\text { new designs }\end{array}$ \\
\hline
\end{tabular}

Table 2. Analysis Model Structure.

\begin{tabular}{|c|l|c|c|c|c|c|}
\hline $\begin{array}{c}\text { Process } \\
\text { Description }\end{array}$ & \multicolumn{1}{|c|}{$\begin{array}{c}\text { Process } \\
\text { Goals }\end{array}$} & $\begin{array}{c}\text { Types of Process } \\
\text { Failures }\end{array}$ & $\begin{array}{c}\text { Efects of Process } \\
\text { Failures }\end{array}$ & $\begin{array}{c}\text { Causes of Process } \\
\text { Failures }\end{array}$ & $\begin{array}{c}\text { Current } \\
\text { Controls }\end{array}$ & $\begin{array}{c}\text { Recommended } \\
\text { Practices }\end{array}$ \\
\hline \multirow{2}{*}{$\begin{array}{c}\text { Dimensional } \\
\text { Management }\end{array}$} & Goal 01 & & & & \\
\cline { 2 - 8 } & G.. & & & & & \\
\cline { 2 - 8 } & Goal 07 & & & & \\
\hline
\end{tabular}

minimize the failures; and (5) the recommended practices, i.e., the suggested actions to prevent each type of failure.

\section{Step 2 - Sampling of dimensional nonconformities}

To identify the types of dimensional variation management failures in the automaker's current process, a sample of nonconformities that occurred late in the company's PDP was collected. The criteria for the sample collection are described below:

- The failures that were considered to be late-occurring nonconformities in the PDP were those that were identified during the construction of prototypes to validate the product and process, i.e., those occurring at the end of the Design Phase and in the Production;

- Only one vehicle design was selected from the automaker's portfolio of existing designs between 2005 and 2010, which had passed through these final stages of the PDP at the time of the survey. The object vehicle of that project is known as "Vehicle X" here to guarantee its confidentiality;

- The final sample consisted of 64 nonconformities relating to dimensional variations that were collected from a global universe of 1000 global nonconformities 
of various types, identified in the construction of the first 200 prototypes of Vehicle X.

A framework was generated for the recording of nonconformities in the sample (see Table 3), with the stage of the PDP in which the nonconformity occurred being shown in the column "Type", the dimensional variation management malfunction that produced the nonconformity being identified in the "Cause" column and the deviation from the recommended practices in the literature shown in the column "Type of Failure".

Due to space limitations, it was not considered feasible in this article to present the descriptions of the 64 nonconformities collected. Instead, the descriptions are presented below for only two nonconformities, which serve to illustrate this step of the research. The complete information was fed into the analysis model (step 4 of the research).

Step 3 - Formulation of proposals for improving practices

Practices aimed at improving the dimensional variation management were proposed at this step based on the malfunctions detected and on the literature reviewed.

\section{Step 4 - Completing the analysis model}

As mentioned above, the data from steps 2 and 3 were released as part of the analysis model. The aim was to obtain a single framework that covered all significant information that supported the proposed improved dimensional variation management process for the automaker.

Step 5 - Proposal of an enhanced dimensional variation management process

With the information collected and generated in the previous steps, it was possible to formulate a proposal for a more robust dimensional variation management process for the automaker. This proposal addresses the recommended activities for achieving each dimensional variation management goal, including integration among the activities. The proposal was made using a series of flowcharts, as shown in the schematic illustration in Figure 3.

\section{Results}

This section presents the data collected and their analyses and suggests an optimized practice model for the automaker's dimensional variation management process.

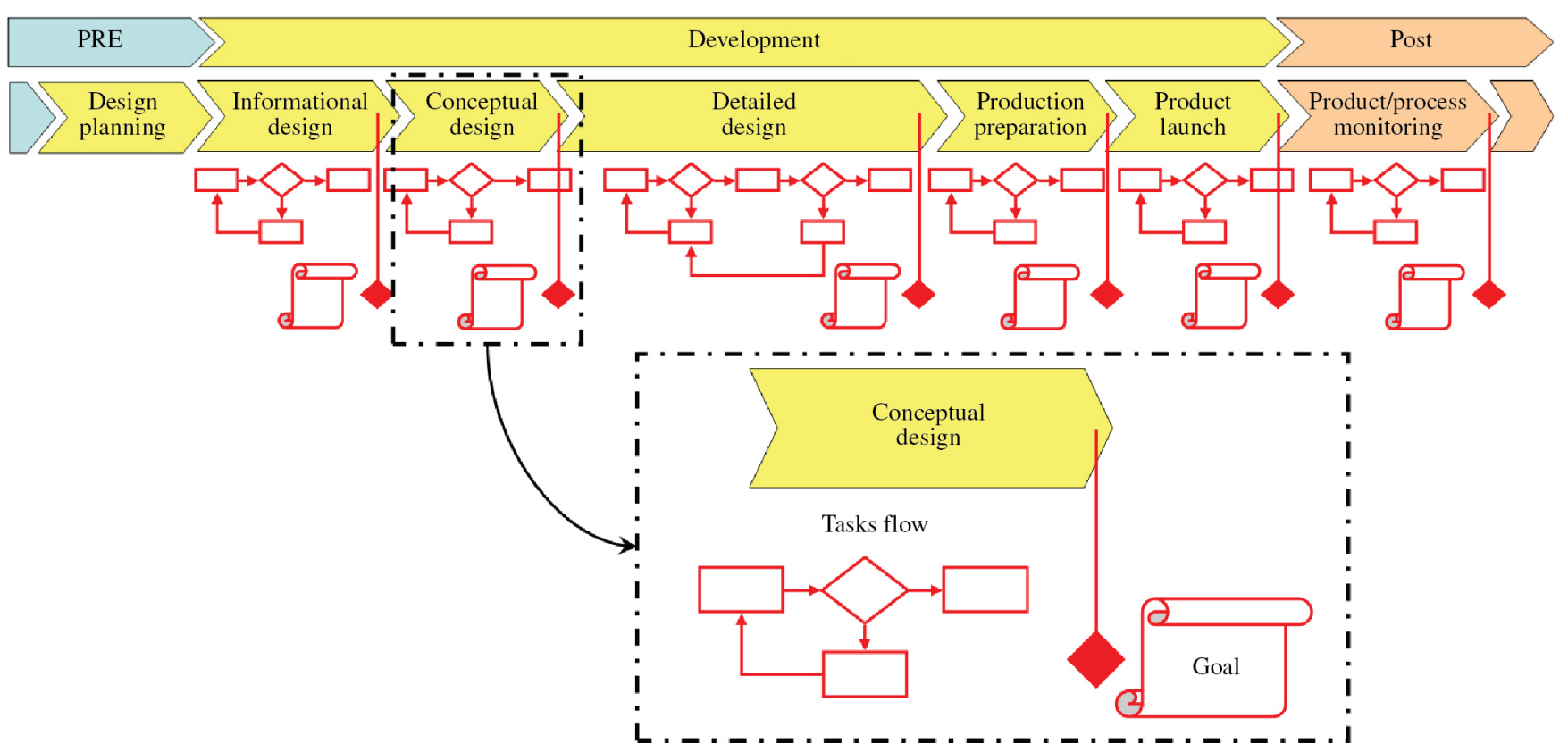

Figure 3. Scheme of the Dimensional Variation Management Process proposed for the automaker.

Table 3. Recording of Vehicle X Nonconformities.

\begin{tabular}{|c|c|c|c|c|}
\hline$\#$ & Nonconformity Description & Type & Cause & Type of Failure \\
\hline 1 & & & & \multirow{2}{*}{ Type 01} \\
\hline 2 & & & & \\
\hline$\ldots$ & & & & \multirow{2}{*}{ Type "n" } \\
\hline 63 & & & & \\
\hline 64 & & & & \\
\hline
\end{tabular}




\subsection{Sampling of dimensional nonconformities}

After construction of the analysis model (step 1 of the empirical research), the sampling of dimensional nonconformities was performed (step 2). As per the nonconformity sampling procedure, two examples of nonconformities that illustrate the analyses of Vehicle X (\#1 and \#4) are presented in Table 4. For these nonconformities, it can be observed that the corresponding types of failure in the automaker's current dimensional variation management process are named "failure type 01 " and "failure type 02 " (Table 4), and descriptions for these are as follows.

Failure type 01 - approval of the design without meeting certain dimensional requirements This type of failure occurs when the product design is submitted for approval and release without proof that the dimensional requirements can be met. This question is related to the lack of a formal verification and approval process for requirements during the development of the design in the Detailed Design Phase.

The example given (nonconformity \#1 in Table 4) is concerned with "interference between the hood and fender (both sides), damaging the paint when opening and closing the hood". In this case, there is a design requirement that specifies a minimum clearance of the hood over its adjacent parts to avoid this type of nonconformity. This example is a functional requirement because when it is not met, the function of opening the hood to allow access to components of the engine compartment is not successfully performed, instead damaging the adjacent parts, either by denting them or by scratching the paintwork.

For nominal clearance to be defined, a minimum clearance must be added to the dimensional variation of the assembly of these parts, which should be determined through dimensional simulations. In the present case, the nominal clearance defined in the design was smaller than the sum of the minimum clearances with dimensional variation, that is, this requirement would not be satisfied with the established design and process conditions. Despite checking this condition and communicating it to the engineering team responsible for the design, it was decided simply to submit the design for approval without complying with this requirement, thereby not accepting the recommendation for increasing the nominal clearance. The result was that the nonconformity occurred when assembling the first prototypes, leading to the need for late design modification (increased nominal clearance), a decision that resulted in a tool change in the manufacture of the hood.

This case exemplifies a failure mode that is directly related to the Detailed Design Phase, linked to Goal 03 of Dimensional Variation Management, which is to determine whether the "optimized" design, manufacturing and assembly processes meet the product requirements.

Failure type 02 - releasing part designs without following the assumptions established in the dimensional simulation analysis

This type of failure is associated with the following two possible causes: (1) the produced pieces do not have the same locators (holes, pins and coupling surfaces) as intended in the design from the dimensional simulation studies; and/ or (2) the specified tolerances in the design are different from those of the aforementioned studies.

The second example given (nonconformity \#4 of Table 4) refers to "misalignment between windshield and roof". Its occurrence is related to the second cause, the non-existence of a hole in the roof, which is responsible for locating/positioning the windshield. The absence of this hole made it more difficult to ensure appropriate positioning of the windshield, which caused a misalignment with the roof and the front columns of the bodywork. This result is undesirable because a non-constant gap between the parts can compromise correct sealing, allowing the ingress of water and dust into the vehicle.

This problem was due to a miscommunication between the dimensional engineering team and the engineering team

Table 4. Details of Vehicle X Nonconformities.

\begin{tabular}{|c|c|c|c|c|}
\hline \# & Nonconformity Description & Type & Cause & \begin{tabular}{|c|} 
Failure Type \\
\end{tabular} \\
\hline 1 & $\begin{array}{l}\text { Interference between the hood and fender (both sides), } \\
\text { damaging the paint when opening and closing the hood }\end{array}$ & \multirow[t]{3}{*}{ Design } & \multirow{3}{*}{$\begin{array}{l}\text { During the Detailed Design phase, } \\
\text { was verified that the involved } \\
\text { requirements could not be } \\
\text { met. However, the design was } \\
\text { submitted for approval anyway. }\end{array}$} & \multirow{3}{*}{$\begin{array}{l}\text { Failure Type } 01 \\
\text { Approval of the design } \\
\text { without meeting certain } \\
\text { dimensional requirements }\end{array}$} \\
\hline 2 & See-through between headlamp and radiator grille & & & \\
\hline 3 & Malfunction lock of rear seats & & & \\
\hline 4 & Misalignment between windshield and roof & \multirow[t]{5}{*}{ Design } & \multirow{5}{*}{$\begin{array}{l}\text { Incompatibility of parts locators } \\
\text { features and tolerances in } \\
\text { comparison between what was } \\
\text { designed/validated in Detailed } \\
\text { Design phase and what was } \\
\text { released for production. }\end{array}$} & \multirow{5}{*}{$\begin{array}{l}\text { Failure Type } 02 \\
\text { Releasing part designs } \\
\text { without following the } \\
\text { procedures assumptions } \\
\text { established in the } \\
\text { dimensional simulation } \\
\text { analysis }\end{array}$} \\
\hline 5 & Misalignment of instrument panel into the body & & & \\
\hline 6 & $\begin{array}{l}\text { Excessive gap among console parts, causing poor } \\
\text { perceived quality }\end{array}$ & & & \\
\hline 7 & $\begin{array}{l}\text { Excessive gap among instrument panel parts, causing } \\
\text { poor perceived quality }\end{array}$ & & & \\
\hline 8 & $\begin{array}{l}\text { Misalignment of taillamp with adjacent parts, causing } \\
\text { poor perceived quality }\end{array}$ & & & \\
\hline
\end{tabular}


responsible for the release of the part designs because at the time of the release, the conditions used in the dimensional simulations were not considered (or respected). This failure results from not accomplishing Goal 04 of dimensional variation management, i.e., ensuring that the dimensional documentation of the product is correct. Included among the many possible consequences of this failure mode are late tool changes and manufacturing price renegotiations with parts suppliers because it can become necessary to redefine tolerances.

\subsection{Formulation of proposals for improving practices}

The improving proposals are as follows (step 3 of the empirical research).

Proposal for avoiding failure type 01 (approval of the design without meeting certain dimensional requirements)

To introduce the proposed improvement that prevents failure type 01 , it was necessary to know in detail the automaker's flow of current activities from the receipt of entry information for the construction of dimensional simulation models to the verification of the requirements to be met to release the design for prototype manufacturing. Figure 4 shows the current flowchart of activities for the aesthetic requirements, emphasizing that the automaker does not have a formal sequence of activities for the verification of the functional requirements.

Briefly, the sequence is as follows: the first stage is to collect all of the information necessary to build the dimensional simulation model. This information includes the intended design (3D model of parts - CAD, locators and tolerances); manufacturing intentions (flow and concept of mounting devices) and the aesthetic requirements of the product. The inclusion of this information means that dimensional simulation models and reports are generated, demonstrating the ability of the design/process to meet the requirements. Those requirements that cannot be met undergo optimization cycles in a set order, first exhausting all possibilities of design change, then process, and finally, if there is no possibility of change, the requirement is changed, widening the specified tolerance. When the requirements can be met, the design is submitted for release. The point of failure in this process is that, even when it is noted that some requirements cannot be met, the design is still submitted for release, as highlighted by the red arrow in Figure 4. It is at this point that the proposal focuses on the enhancement of practices to eliminate failure type 01 .

The proposed enhancement of practices to prevent this type of failure employs an electronic system (database) used by the automaker into which requirements are input and conformity with them is controlled. Thus, dimensional requirements, both aesthetic and functional, would be entered into this system, defining targets to be met at each stage, and all design/process verification would be achieved using the system. Likewise, the system would be used to generate achievement progress reports according to the previously defined frequency. The suggested flowchart of

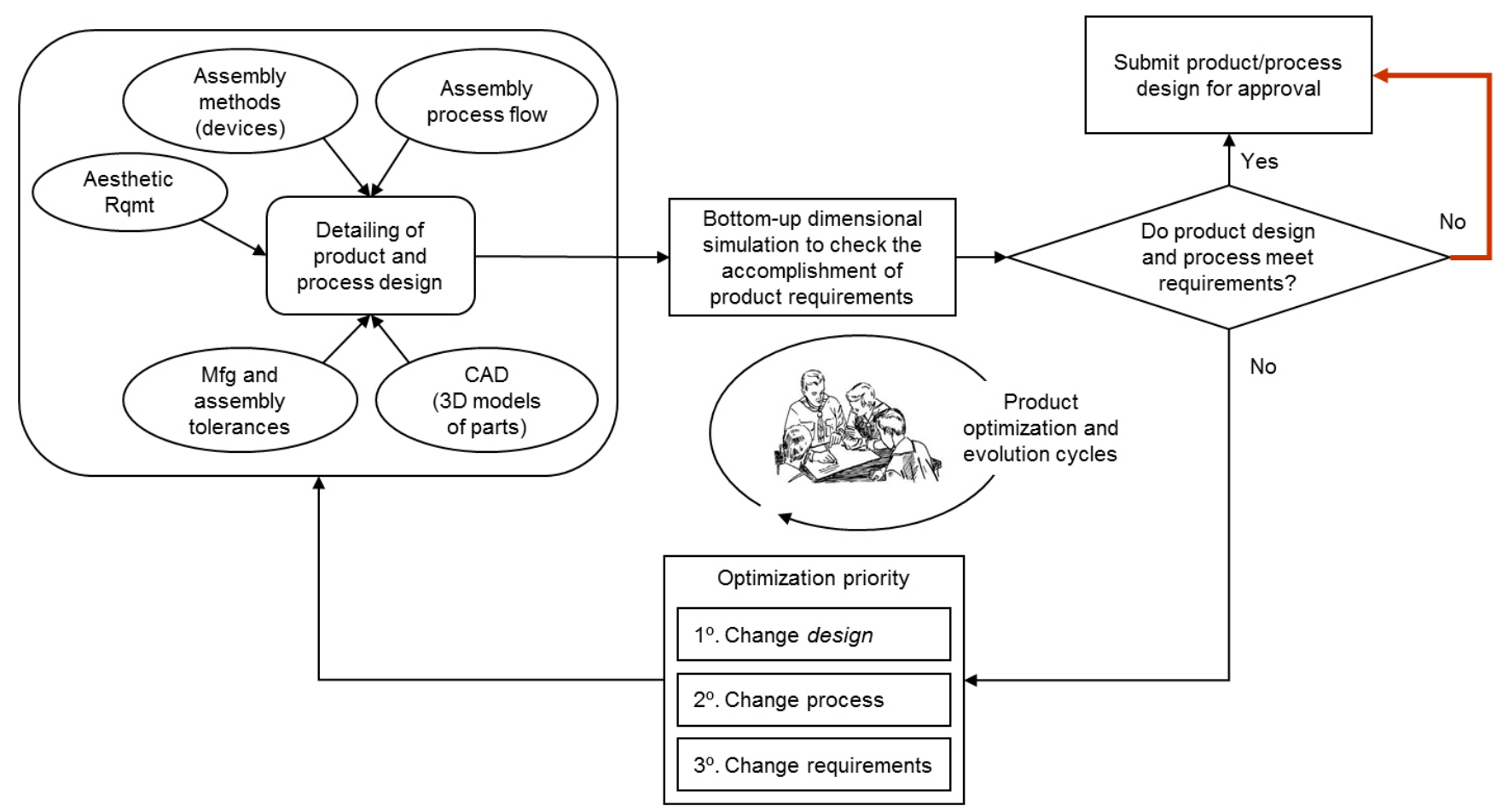

Figure 4. Current flowchart for achieving approval for aesthetic requirements. 
activities is as configured in Figure 5, where improvement actions are highlighted in blue.

In terms of roles and responsibilities, it is proposed that the Dimensional Engineering team is assigned responsibility for feeding the dimensional requirements into the system, making evaluations and reporting progress to the senior management of the automaker. These changes should be promoted by working in conjunction with other engineering and manufacturing teams.

This process ensures the formal evaluation of all requirements in the development of the product.

Proposal to prevent failure type 02 (releasing part designs without following procedures from the dimensional simulations)

It is easy to see that it would be counterproductive to form a team and devote time and resources to performing dimensional simulation analysis and later, at the moment that designs are submitted for approval/release, not to implement the findings of the analyses. To try to curb this communication problem, the automaker under study already has a document that aims to disclose all intended procedures for the design and process that are used to build the dimensional model. This document consolidates the input data of the various engineering and manufacturing teams that are involved with the development of the product design and is used to illustrate the optimization proposals. As the design of the product and process evolve, this document will also be updated and revised throughout the Detailed Design Phase until the dimensional requirements of the product are fulfilled. Figure 6 shows how these activities (highlighted in yellow) are currently included in the dimensional requirements verification flowchart.

A discontinuity can be observed in the information in the aforementioned flow, i.e., the revision with the engineering and manufacturing teams does not connect with any other activity. It is here that the problem occurs that leads to failure type 02. Most of the time, even when all work alignment has been performed, the concepts contained in the document that will feed into the dimensional model are simply not implemented in the design, and the latter is submitted for approval/release without those concepts. This failure of implementation occurs because the document in question is not a formal handover of the automaker's product development process, which means that the engineering and manufacturing teams may not follow the recommendations, particularly in the case of design changes.

What needs to be undertaken, therefore, is to formalize the document by requiring its approval by all of the parties

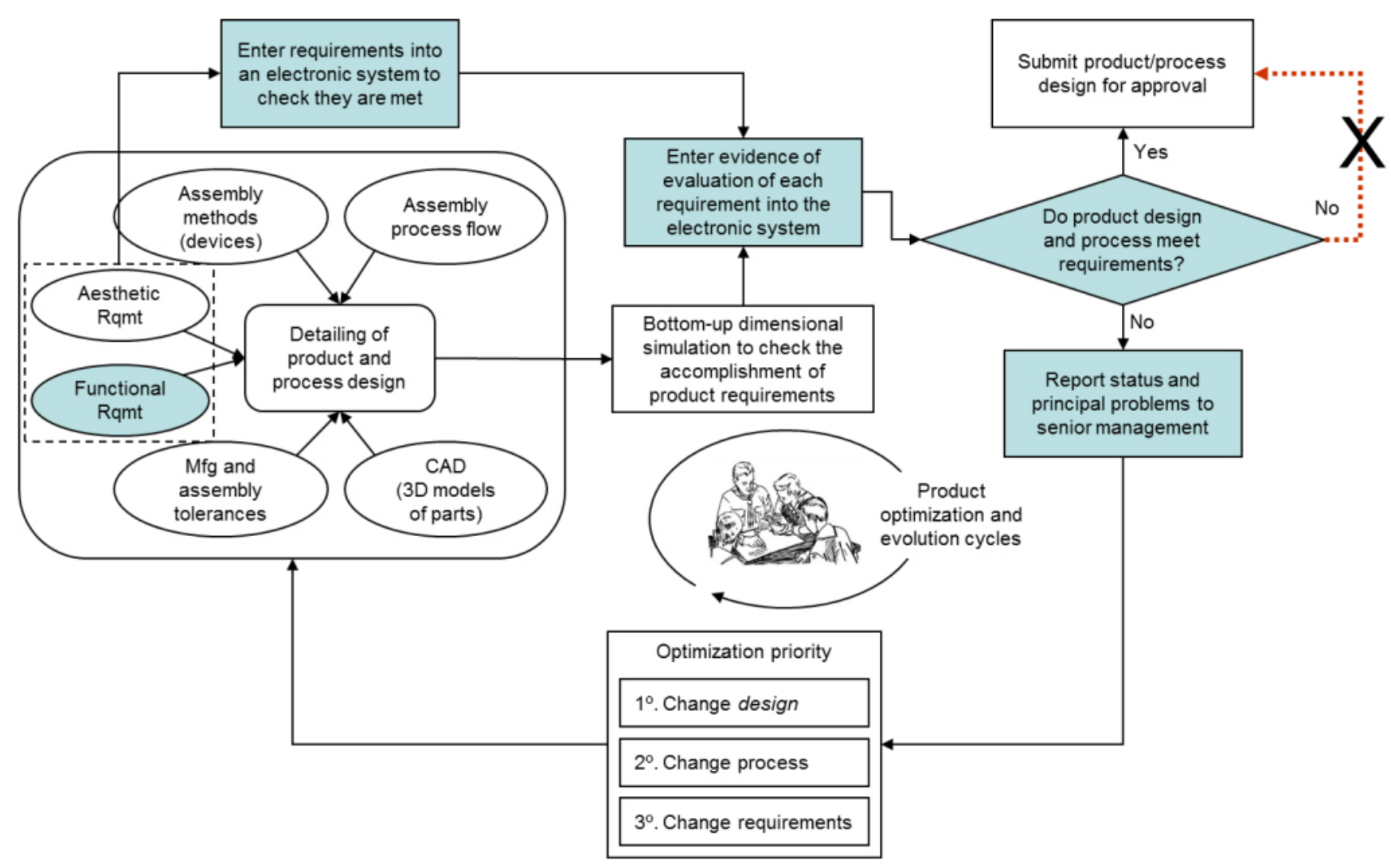

Figure 5. Proposed flowchart for achieving approval of dimensional requirements. 


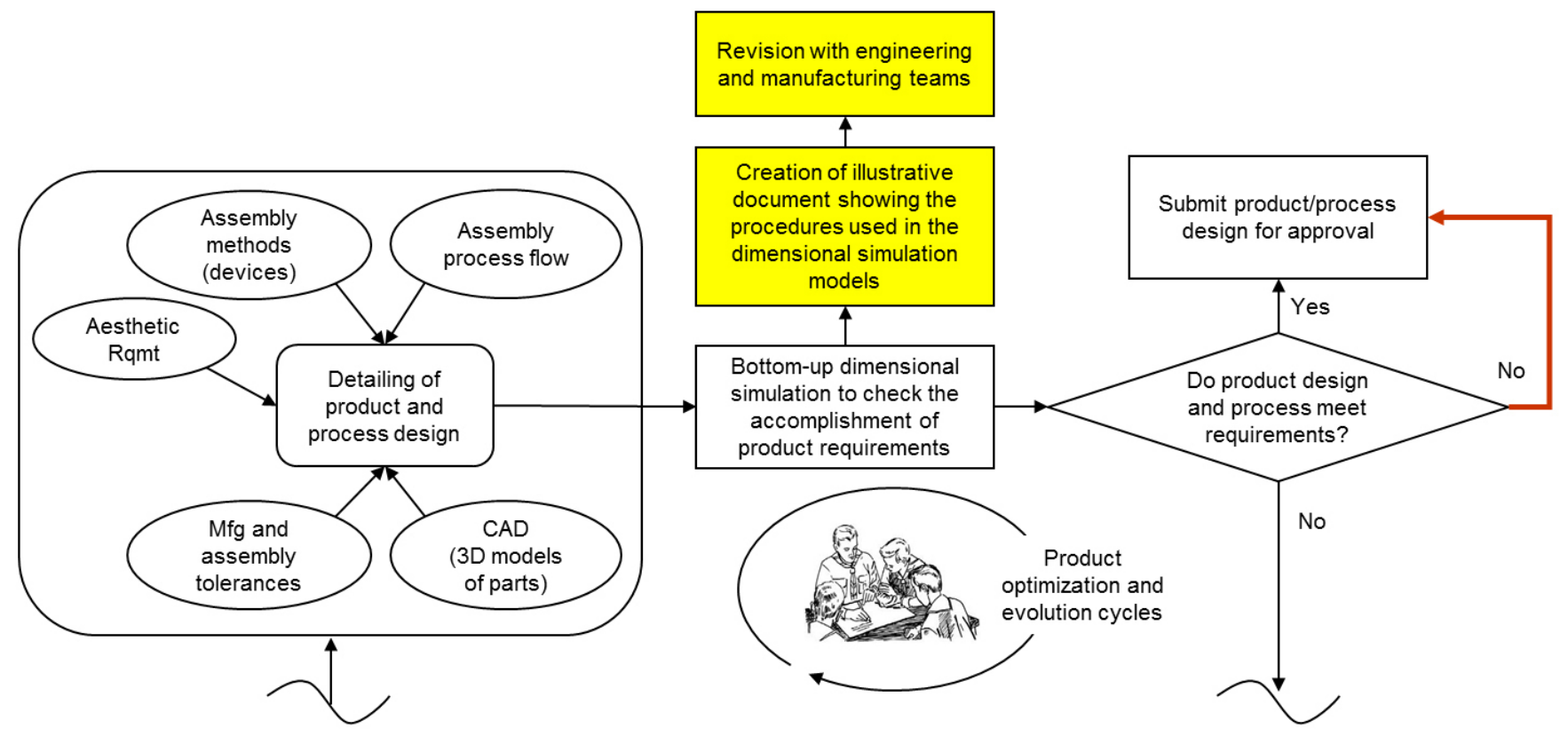

Figure 6. Current flowchart of the dimensional requirements verification process.

involved, using it as evidence of design/process solutions to meet the requirements. As in the example of the practice enhancement proposal to eliminate failure type 01, this evidence would also be inserted into the same electronic system (database), which would mean that in the event of impossibility of implementation, as a minimum, a further analysis would be required to assess the new design configuration that is intended for release. Furthermore, a final compatibility check should be made of the design in relation to this document at the point at which designs are submitted for approval/release. This process will ensure that the product dimensional documentation is correct. Figure 7 shows the improved sequence of activities in the proposed flowchart for the approval of dimensional requirement achievements. Similarly, improvement activities are highlighted in "blue".

In terms of roles and responsibilities, checking the coherence of the designs submitted to the release process and the information contained in the design and process concept consolidation document would be the responsibility of the Dimensional Engineering team.

\subsection{Completing the analysis model}

As outlined in the Methodology section, the Analysis Model, the structure of which is shown in Table 2, was filled with the information collected in the study, complying step 4 of the empirical research. Table 5 shows the details of the completed Analysis Model, containing only the summary information relating to two nonconformities. As already mentioned, these were chosen as illustrations for this text due to the lack of space for reporting the entire dataset for the 64 (sixty-four) nonconformities investigated for the automaker.

\subsection{Proposal of an enhanced dimensional variation management process}

The final stage of the research (step 5) was to include the set of proposed improvements in the generic PDP model used for the study, thus building an articulated and optimized dimensional variation management process for the automaker. Figure 8 shows the details of this process, illustrating the actions required to achieve goals 03 and 04 of the dimensional variation management for the illustrative examples used in this article.

As the two types of failures used to illustrate this article focus on the Detailed Design Phase, only that portion of the PDP is shown in Figure 8. Obviously, the entire process of dimensional variation management comprises all of the other phases of the PDP such that the complete set of improvement practices suggested from the analysis of the 64 nonconformities of the sample covers all phases of the PDP and focuses on the 7 goals of dimensional management.

\section{Conclusions}

The analyses conducted on the total sample of nonconformities, which were illustrated in this paper by two examples, allowed us to meet the objective of proposing improvements to the automaker's dimensional variation management process. From this point on, there are to be clearly defined roles and responsibilities for executing improved dimensional variation management activities in the company's PDP. By implementing the proposed 


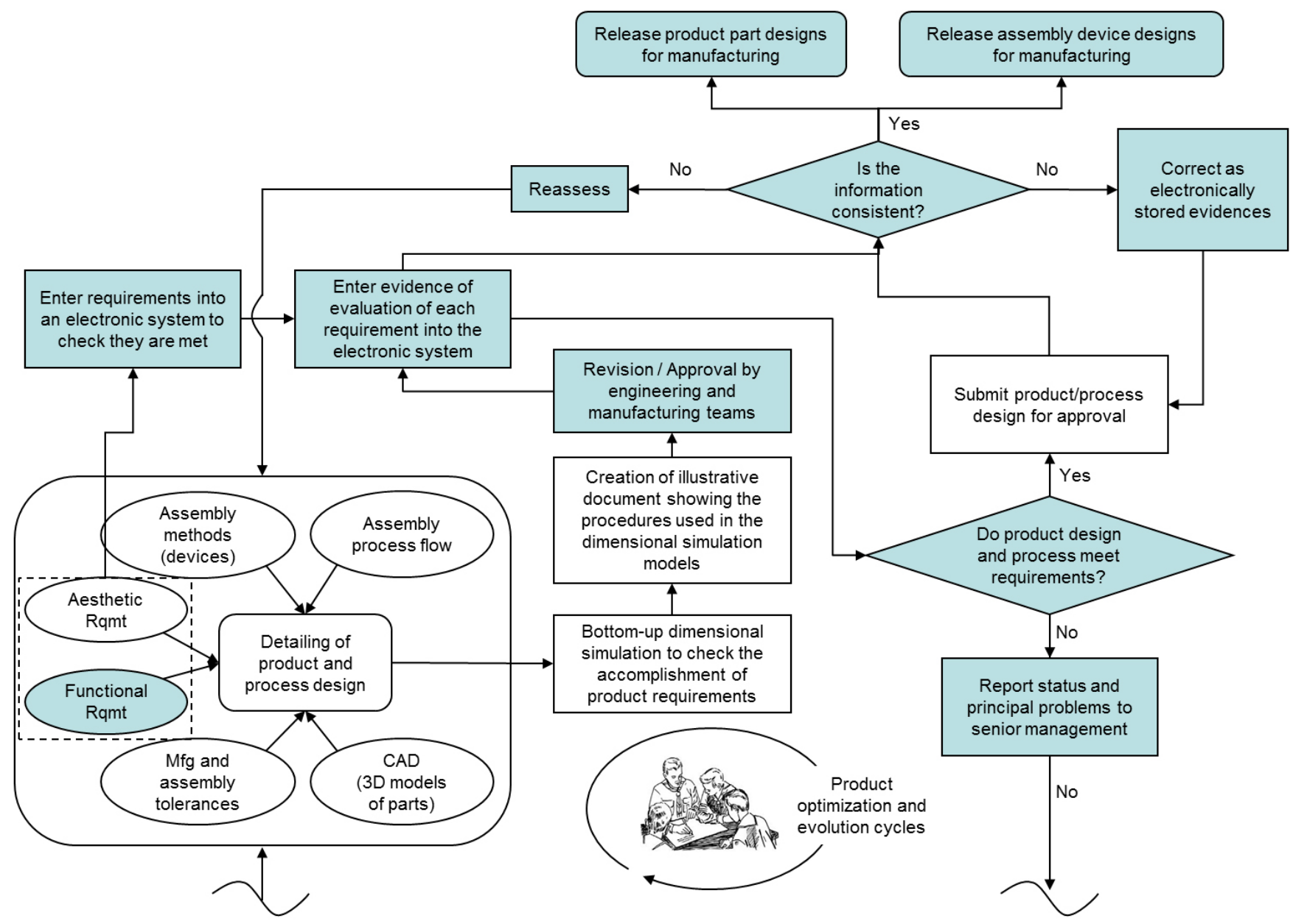

Figure 7. Proposed integration of design release with the results of the simulation dimensional analyses.

actions, improvements can be measured/observed in future product development programs by comparing the reduction of number of dimensional nonconformities identified at the end of Product Design (prototype build), Production Preparation and Post-Development phases. Also the need for increased interaction of multi-functional teams to meet DDC objectives is expected to be observed, which promotes the concurrent engineering in order to deliver more robust products.

This study showed that dimensional variation management is a subject that is relevant throughout the development and post-development cycle of the product. This cycle begins with identifying and translating the "voice of the customer" into measurable technical requirements; it goes through the stages of conceptual and detailed designs, which utilize dimensional simulation models; and proceeds to the validation of the prototypes, processes and production of the product, which employ the SPC for monitoring the relevant characteristics of the product. This process leads to the right conditions for accomplishing the established requirements. The study also showed the importance of feedback for the development of new products, with information coming from production to seek continuous quality improvement and thus close the cycle of a robust dimensional variation management process. It can be observed that the interactions are not necessarily in sequential form in the proposed dimensional variation management process. Rather, the interactions have the characteristics of a typical concurrent engineering working process with constant review of the design and process alternatives until agreement is reached on an optimized solution, ideally before commitment to the tool production.

It is also clear that the main facilitator of dimensional variation management is the dimensional simulation system, which is the engineering instrument that verifies that the optimized design and process are able to meet the product requirements. If these requirements are not met, the dimensional simulation immediately offers proposed development and engineering solutions with product or process modifications without the need to build physical prototypes for testing by trial and error. Thus, this method saves time and money in the development of 


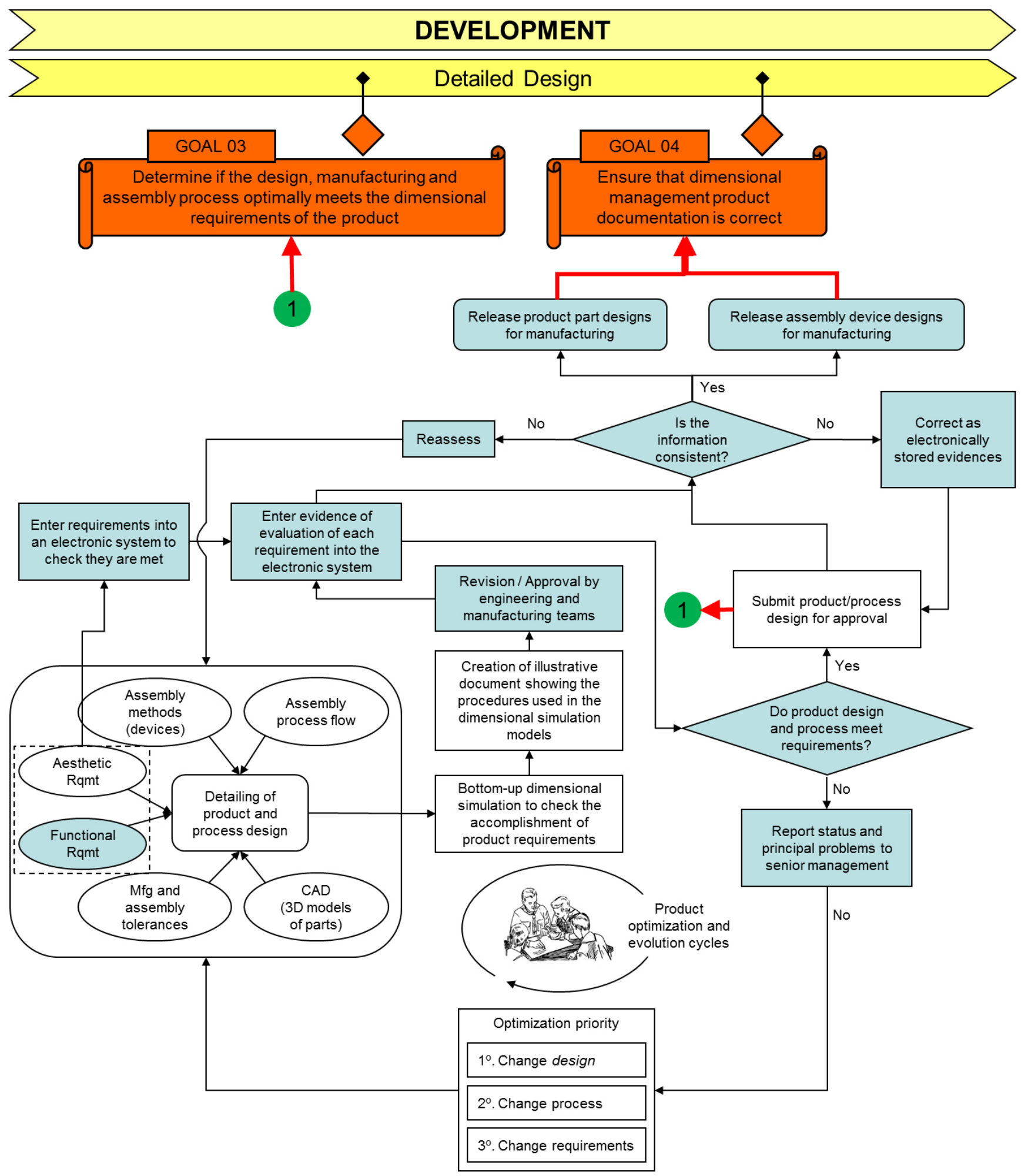

Figure 8. Details of the proposed dimensional variation management process (excerpt concerning the fulfillment of goals 03 and 04).

new products. Simulation models are able to specify the relevant characteristics of the product and their allowable tolerances, which will facilitate the development of robust Manufacturing Control Plans. Aligned to the SPC, these plans will be able to monitor and anticipate nonconformities in the early stages of the assembly process. This process operates in a preventative manner, so that waste, adjustments and repair operations, known as "the hidden factory", are 
Table 5. Detail of completed Analysis Model.

\begin{tabular}{|c|c|c|c|c|c|c|}
\hline $\begin{array}{c}\text { Process } \\
\text { Description }\end{array}$ & Process Goals & $\begin{array}{c}\text { Types of Process } \\
\text { Failures }\end{array}$ & $\begin{array}{c}\text { Effect of Process } \\
\text { Failures } \\
\end{array}$ & $\begin{array}{c}\text { Cause of Process } \\
\text { Failures } \\
\end{array}$ & $\begin{array}{l}\text { Current } \\
\text { Controls }\end{array}$ & $\begin{array}{l}\text { Recommended } \\
\text { Practices }\end{array}$ \\
\hline $\begin{array}{l}\text { Dimensional } \\
\text { Management }\end{array}$ & $\begin{array}{l}\text { GOAL 01 } \\
\text { Clearly define } \\
\text { product dimensional } \\
\text { requirements (aesthetic } \\
\text { and functional) }\end{array}$ & \multicolumn{5}{|c|}{ NOT COVERED IN THIS ARTICLE } \\
\hline & $\begin{array}{l}\text { GOAL } 02 \\
\text { Evaluate the technical } \\
\text { dimensional feasibility } \\
\text { of the product design } \\
\text { concepts }\end{array}$ & \multicolumn{5}{|c|}{ NOT COVERED IN THIS ARTICLE } \\
\hline & $\begin{array}{l}\text { GOAL 03 } \\
\text { Determine if the } \\
\text { design, manufacturing } \\
\text { and assembly process } \\
\text { optimally meets } \\
\text { the dimensional } \\
\text { requirements of the } \\
\text { product }\end{array}$ & $\begin{array}{l}\text { Failure Type } 01 \\
\text { Approval of the } \\
\text { design without } \\
\text { meeting certain } \\
\text { dimensional } \\
\text { requirements }\end{array}$ & $\begin{array}{l}\text { Not meet certain } \\
\text { requirements } \\
\text { of the product; } \\
\text { L a t e desig n } \\
\text { changes; } \\
\text { Need for severe } \\
\text { control in the } \\
\text { manufacturing } \\
\text { process, raising the } \\
\text { cost of production }\end{array}$ & $\begin{array}{l}\text { S u b m i t the } \\
\text { project for } \\
\text { approval without } \\
\text { proving that the } \\
\text { requirements have } \\
\text { been met }\end{array}$ & $\begin{array}{l}\text { Only the aesthetic } \\
\text { requirements } \\
\text { are submitted } \\
\text { for verification, } \\
\text { however no proof } \\
\text { of compliance with } \\
\text { these is guaranteed } \\
\text { because there is no } \\
\text { systematic control }\end{array}$ & $\begin{array}{l}\text { Include the } \\
\text { a esthetic and } \\
\text { functional } \\
\text { requirements in an } \\
\text { electronic system } \\
\text { of verification } \\
\text { a n d p r o o f } \\
\text { requirements; } \\
\text { Establish goals } \\
\text { as the maturity of } \\
\text { the project; Report } \\
\text { status to the senior } \\
\text { management } \\
\text { of Prod c t } \\
\text { Development }\end{array}$ \\
\hline & $\begin{array}{l}\text { GOAL 04 } \\
\text { Ensure that dimensional } \\
\text { management product } \\
\text { documentation is } \\
\text { correct }\end{array}$ & $\begin{array}{l}\text { Failure Type } 02 \\
\text { Releasing part } \\
\text { designs without } \\
\text { following the } \\
\text { procedures } \\
\text { assumptions } \\
\text { established in } \\
\text { the dimensional } \\
\text { simulation } \\
\text { analysis }\end{array}$ & $\begin{array}{l}\text { Approve out } \\
\text { of dimensional } \\
\text { specification } \\
\text { parts, and reject } \\
\text { within ones; } \\
\text { Occurrence } \\
\text { of unexpected } \\
\text { nonconformities; } \\
\text { Late changes of } \\
\text { manufacturing } \\
\text { tooling; } \\
\text { Need for costs } \\
\text { renegotiating with } \\
\text { suppliers due to } \\
\text { tighten tolerances }\end{array}$ & $\begin{array}{l}\mathrm{L} \text { a c k o f } \\
\text { communication } \\
\text { among } \\
\text { engineering teams } \\
\text { during the product } \\
\text { development }\end{array}$ & $\begin{array}{l}\text { None: both } \\
\text { engineering } \\
\text { responsible for } \\
\text { design release and } \\
\text { manufacturing, } \\
\text { may choose to } \\
\text { adopt or not a } \\
\text { recommendation } \\
\text { from dimensional } \\
\text { team, without } \\
\text { further analysis is } \\
\text { needed to verify } \\
\text { the feasibility of } \\
\text { the new concept }\end{array}$ & $\begin{array}{l}\text { Integrate the } \\
\text { activity of design } \\
\text { release with } \\
\text { verification of } \\
\text { assumptions used } \\
\text { in simulation } \\
\text { models } \\
\text { dimensional }\end{array}$ \\
\hline & $\begin{array}{l}\text { GOAL 05 } \\
\text { Validate the product } \\
\text { dimensional } \\
\text { requirements against } \\
\text { the physical prototypes }\end{array}$ & \multicolumn{5}{|c|}{ NOT COVERED IN THIS ARTICLE } \\
\hline & $\begin{array}{c}\text { GOAL 06 } \\
\text { Verify if manufacturing } \\
\text { capabilities achieve } \\
\text { design intent }\end{array}$ & \multicolumn{5}{|c|}{ NOT COVERED IN THIS ARTICLE } \\
\hline & $\begin{array}{l}\text { GOAL } 07 \\
\begin{array}{l}\text { Production to design } \\
\text { feedback loop }\end{array}\end{array}$ & \multicolumn{5}{|c|}{ NOT COVERED IN THIS ARTICLE } \\
\hline
\end{tabular}


reduced. The use of such models is relevant to virtually all of the product development cycle with different applications. Among these applications are (a) "qualitative" analyses in the conceptual phases, where design concepts, mounting devices and similar assembly process capabilities are compared, (b) "quantitative" analyses that provide the detailed design with definitions, tolerances and location schemes for each piece of the product and (c) analyses that are intended to represent real process capability conditions, usually as they are implemented in the product's production and launch phases.

Dimensional variation management therefore helps to reduce the development time and production costs by making designs more robust to dimensional variation, which paves the way for less stringent manufacturing controls and the reduced need for operational adjustments and repairs. The production cycle is also reduced, increasing the automaker's productivity. As a result, it is hoped that quality products at a lower cost are launched more quickly onto the market and will provide a large competitive advantage for the automaker, thus underlining the importance of dimensional variation management as a facilitator of business goals.

Finally, it is important to note that due to the need for the involvement of several multi-functional teams in the effort to meet the goals of dimensional variation management, the implementation of this discipline should become one of the automaker's senior management objectives.

\section{References}

CRAIG, M. Dimensional Management versus Tolerance Assignment. Assembly Automation, 1996. v. 16, p. 12-16. http://dx.doi.org/10.1108/01445159610117645

CRAIG, M. Dimensional Management: a Necessary Process to Meet Corporate Goals for Global Competition. In: COLLOQUIUM OF CONTROL OF DIMENSIONAL VARIATION, 1997, Birmingham. Proceedings... Birmingham, 1997.

DANTAN, J.-Y. et al. Geometrical product specifications - model for product life cycle. Computer-Aided Design, v. 40, p. 493514, 2008a. http://dx.doi.org/10.1016/j.cad.2008.01.004
DANTAN, J.-Y. et al. Information modeling for variation management during the product and manufacturing process design. International Journal on Interactive Design and Manufacturing, n. 2, p. 107-118, 2008b.

HARPER, A. P. Jaguar's approach to Dimensional Control in Product Development. In: COLLOQUIUM OF CONTROL OF DIMENSIONAL VARIATION, 1997, Birmingham. Proceedings... Birmingham, 1997. http:// dx.doi.org/10.1049/ic:19971167

HUANG, G. Q. Design for X: Concurrent Engineering Imperatives. London: Chapman \& Hall, 1996. http://dx.doi. org/10.1007/978-94-011-3985-4

ILLINGWORTH, T.; McLEOD, N. Managing Tolerances at Nissan. June 2007. Available from: <www.iconasolutions. com>. Access in: Feb 2012.

ISLAM, M. N. A Dimensioning and Tolerancing Methodology for Concurrent Engineering Applications II: Comprehensive Solution Strategy. International Journal on Interactive Design and Manufacturing, n. 42, p. 922-939, 2009.

LEANEY, P. G. Assessing Best Practice in Dimensional Management and Control of Variation in Automobile Build. Department of Manufacturing Engineering, 1994.

LIGGETT, J. V. Dimensional Variation Management Handbook: a guide for quality, design, and manufacturing engineers. New Jersey: Prentice Hall, 1993. PMCid:PMC46362.

MUSKE, S. Application of Dimensional Management on 747 Fuselage. In: SEMINAR ON TOLERANCING AND ASSEMBLING MODELING, 1997. Proceedings... 1997. PMid:9268116.

PERCEIVED QUALITY JOURNAL. Dec 2011. Available from: <www.pqjournal.com>. Access in: Feb 2012.

ROZENFELD, $\mathrm{H}$. et al. Gestão de Desenvolvimento de Produtos: uma referência para a melhoria do processo. São Paulo: Saraiva, 2006.

SLEATH, D.; LEANEY, P. Control of Dimensional Variation and Integrated Product Development. In: COLLOQUIUM OF CONTROL OF DIMENSIONAL VARIATION, 1997, Birmingham. Proceedings... Birmingham, 1997. http:// dx.doi.org/10.1049/ic:19971162 